\title{
A method for recognising non-bacterial prostatitis:
}

\section{Preliminary observations}

\author{
P D SIMMONS* AND R N THIN† \\ From the Departments of Genitourinary Medicine, *St Peter's Hospital and †St Thomas' Hospital, \\ London
}

SUMMARY Chronic non-bacterial prostatitis is a difficult condition to diagnose accurately either by symptoms and signs or by investigations. Four groups of patients were assessed for the number of leucocytes and the presence of pathogens in expressed prostatic secretions before and after treatment with co-trimoxazole two tablets twice daily for three months. The pretreatment findings suggest that the upper limit of normal for the number of leucocytes in expressed prostatic secretions is about five per microscope field ( $\times 40$ magnification) and that for the cell count about $0.5 \times 10^{9} / 1$ using the method described. Increased microscopical cell estimations and cell counts in the expressed prostatic secretions of patients with symptoms of prostatitis and those with recurrent non-specific urethritis seem to indicate the presence of prostatitis.

\section{Introduction}

Acute prostatitis is now rare but can be readily recognised from the symptoms and clinical examination of the prostate. Chronic prostatitis is more common but is more difficult to diagnose. In patients who present with perineal discomfort, difficulty in micturition, localised tenderness of the prostate, and a typical urinary pathogen such as Escherichia coli, subacute or chronic prostatitis can be readily diagnosed. Other patients present greater difficulty and the urinary tract localisation studies of Meares and Stamey showed that urinary pathogens may be found in greater numbers in the expressed prostatic secretion (EPS) obtained by prostatic massage than in urine samples passed before or after prostatic massage. ${ }^{1}$ In many patients, however, no pathogen is isolated.

Another method of diagnosing chronic prostatitis is by simple microscopy of the EPS. Unfortunately, confusion exists about criteria for normal and abnormal secretion, which is usually assessed in terms of numbers of leucocytes per microscope field. A generally accepted upper limit of normal is 10 leucocytes per microscope field $(\times 40) .{ }^{23}$ Some apparently healthy men have abnormal numbers of cells by these criteria. ${ }^{2}$ It is generally agreed, however, that the presence of clumps of leucocytes in

Address for reprints: Dr R N Thin, Department of Genitourinary Medicine, St Thomas' Hospital, London SE1 7EH

Accepted for publication 5 April 1983 the EPS is abnormal. A more accurate microscopical method which has been suggested is to collect five drops separately but this is a cumbersome process. ${ }^{2}$

As in the past no pathogen has been isolated in most of our patients in whom prostatitis was suspected $^{4}$ we decided to carry out simple microscopy and cell count in addition to quantitative bacteriological examination of the EPS from patients in whom prostatitis was suspected.

One group of patients in whom prostatitis might be present in the absence of symptoms is men with recurrent non-specific urethritis (NSU). These men take up much time in genitourinary medicine departments in the United Kingdom. For this reason we studied a group of these patients with NSU, a group with no history of NSU but with symptoms suggesting prostatitis, and a group of patients with a history of NSU and symptoms suggesting prostatitis. For comparison we also studied a group of subjects in whom prostatitis was not suspected.

\section{Patients and methods}

\section{STUDY POPULATION}

The patients comprised: $(a)$ men with documented recurrent NSU (each episode fulfilling the criteria of Alani $e^{t} a^{5}$ ) but no symptoms suggesting prostatitis; (b) men with symptoms suggesting prostatitis and no history of NSU; and (c) men with a history of recurrent NSU and symptoms suggesting prostatitis (NSU/prostatitis). Recurrent NSU was defined as at least three previous episodes in an unlimited period. 
Control subjects were informed volunteers from among patients attending departments of genitourinary medicine in whom there was no evidence of current sexually transmitted disease (STD) or lower genitourinary tract disease, no past history of these diseases, and no known contact with STD. The local ethical committee agreed that these men might be studied.

\section{PROSTATIC ASSESSMENT}

All patients and controls underwent a full clinical examination. Early morning assessment was then carried out to exclude urethritis ${ }^{6}$ and a midstream urine (MSU) specimen was examined. If these tests were all normal prostatic assessment was carried out.

Collection of prostatic secretions-All patients and controls were asked to attend with a full bladder and to abstain from ejaculation for at least seven days beforehand. Initially, the full technique described by Meares and Stamey was followed ${ }^{1}$ but no information at all was obtained from the first catch urine specimen (voided bladder urine 1 (VB1)) or the second catch urine specimen (voided bladder urine 2 (VB2)) so these were subsequently collected and examined macroscopically. If they appeared clear they were discarded and prostatic examination was carried out. No attempt was made to drain urine from the distal urethra. The prostate was examined digitally one to three minutes after micturition and, provided that no tenderness was experienced, massage was then performed with the prepuce retracted and a sterile container held at the end of the penis. Expressed prostatic secretions dropped from the meatus into the container. The urethra was then massaged distally to obtain more secretion and finally a drop was collected on a slide. The material in the sterile container was vigorously mixed by hand. The patient then passed a third urine sample (voided bladder urine 3 (VB3)). The volume of the urine samples was about $25 \mathrm{ml}$.

Microscopy of secretions-Microscopy of the EPS was performed within five minutes of collection by one observer using the $\times 40$ objective of the microscope. The final estimate was the mean of the cells and clumps in at least 20 microscope fields. A clump was defined as an aggregation of two or more leucocytes. Cell counts were performed at the same time by an independent observer using a modified Fuchs-Rosenthal haematological counting chamber.

Culture of urine and secretions-Semiquantitative cultures of urine were undertaken using the filter paper method $^{7}$; paper strips were supplied by Mast Laboratories and were inoculated on to purple serum agar (Oxoid). Cultures of the EPS were performed by the standard loop technique with inoculation on to purple serum agar (Association of Clinical Patholo- gists; estimation of bacteria and white cells in the urine, Broadsheet 80, 1973). Micro-organisms were identified by the standard methods of Cowan and Steel. ${ }^{8}$

Pretreatment studies were repeated in several patients, but for ethical reasons these were limited to those in whom the original findings were considered to be at variance with the clinical picture. The interval between the studies varied from two to four weeks. Patients were treated with co-trimoxazole two tablets twice daily for three months and the studies repeated.

Statistical comparisons were made by the $\chi^{2}$ test, the Mann-Whitney U test, and McNemar's test.

\section{Results}

Twenty eight patients with recurrent NSU, eight with symptoms suggesting prostatitis (minimum features were recurrent or persistent dysuria with or without frequency and perineal discomfort or pain), and three with NSU/prostatitis, and 28 controls were studied.

The age of the patients ranged from 22 to 58 years with a mean of $32 \cdot 7$ years and a mode of 30 years. The age of the controls ranged from 19 to 52 years with a mean of 34.4 years and a mode of 32 years. Thirty six patients and 24 controls were white. Thirty patients were single, six married, and three divorced. Six controls were single, 18 married, and four separated. The age distribution and racial origin of patients and controls were similar, but the distribution of marital state was significantly different $\left(\chi_{1}^{2}\right.$ $14 \cdot 89, \mathrm{p}<0 \cdot 001)$.

\section{MICROSCOPICAL FINDINGS}

Fig 1 shows the microscopical estimation of numbers of leucocytes in the EPS of patients and controls. The mean estimate for patients was $6 \cdot 3$ cells per microscope field and for controls 3.0 cells per microscope field. The distributions looked different and this was supported when the data were analysed by the Mann-Whitney $U$ test $(\zeta=3.23, p<0.001)$, which showed that there were significantly more cells in the EPS of all patients than in that of the controls.

Table I shows that clumping of leucocytes in the EPS (one small clump to many large clumps) was present in the secretion from 24 patients and in that from only six controls, which was a significant difference ( $p<0.001$ in all comparisons by the $\chi^{2}$ test).

\section{LEUCOCYTE COUNTS}

Fig 2 shows the distribution of leucocyte counts in EPS from patients and controls. The mean number of cells for patients was $0.535 \times 10^{9} / 1$ and for controls $0.183 \times 10^{9} /$ l. The distributions looked 

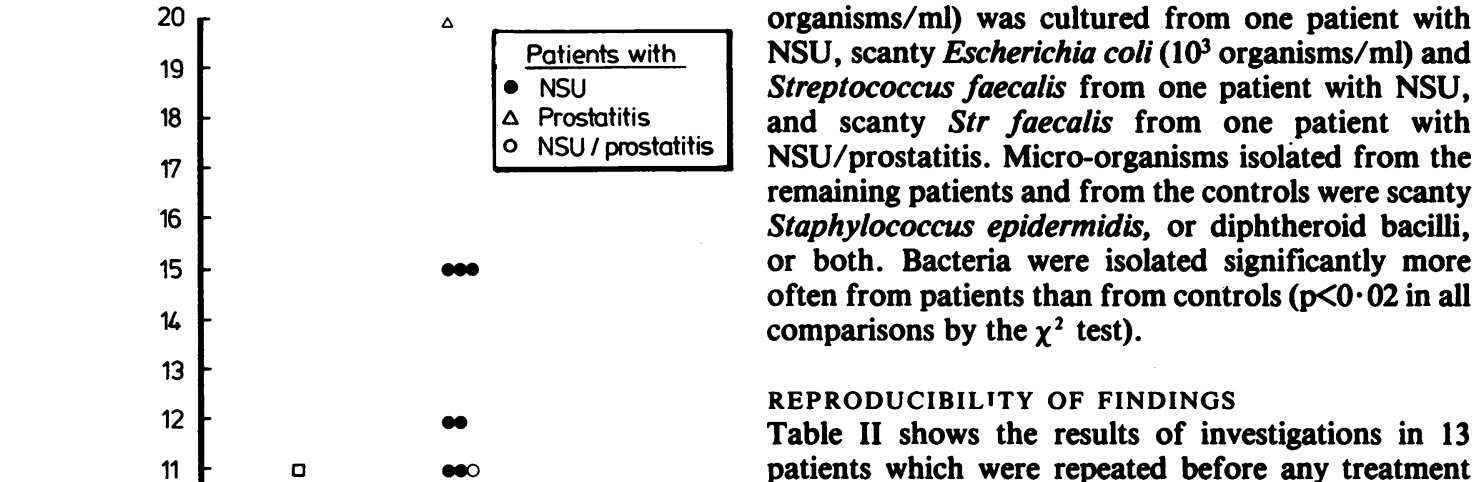

Cells/field

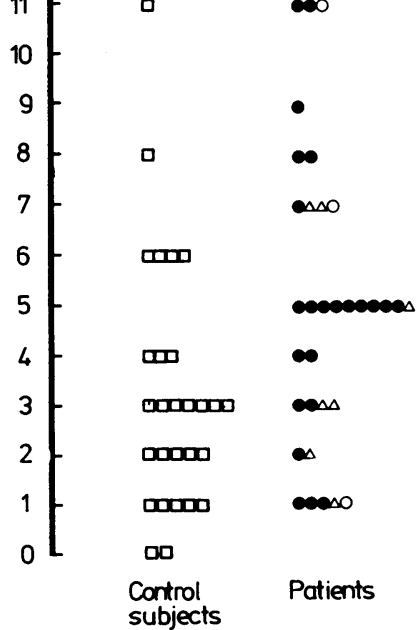

FIG 1 Microscopical estimations of leucocytes in expressed prostatic secretions of patients and controls.

TABLE I Number of men with clumping of leucocytes and the presence of micro-organisms in expressed prostatic secretions

\begin{tabular}{lrll}
\hline Group & $\begin{array}{l}\text { No in } \\
\text { group }\end{array}$ & $\begin{array}{l}\text { No (\%) with } \\
\text { clumping of } \\
\text { leucocytes }\end{array}$ & $\begin{array}{l}\text { No with micro- } \\
\text { organisms }\end{array}$ \\
\hline Men with: & & & \\
$\quad$ NSU & 28 & $19(67 \cdot 8)$ & 15 \\
Prostatitis & 8 & $5(62 \cdot 5)$ & 5 \\
NSU/prostatitis & 3 & 0 & 2 \\
Controls & 28 & $6(21 \cdot 4)$ & 5 \\
\hline
\end{tabular}

different and this was supported by analysis using the Mann Whitney $U$ test $(\zeta=2.93$, $p<0.002)$. This agreed with the previous finding of significantly more cells in the EPS of patients than in that of controls.

\section{MICROBIOLOGICAL FINDINGS}

Table I shows that bacteria were isolated from 22 patients and five controls. Proteus mirabilis $\left(10^{5}\right.$ organisms $/ \mathrm{ml}$ ) was cultured from one patient with NSU, scanty Escherichia coli $\left(10^{3}\right.$ organisms $\left./ \mathrm{ml}\right)$ and Streptococcus faecalis from one patient with NSU, and scanty Str faecalis from one patient with NSU/prostatitis. Micro-organisms isolated from the remaining patients and from the controls were scanty Staphylococcus epidermidis, or diphtheroid bacilli, often from patients than from controls ( $0<0.02$ in all comparisons by the $\chi^{2}$ test).

\section{REPRODUCIBILITY OF FINDINGS}

Table II shows the results of investigations in 13 patients which were repeated before any treatment was given. No significant differences between the two sets of results were found in the microscopic estimation of cells, the presence of clumping, the EPS cell counts, or the number of patients with saprophytic organisms.

In microscopic cell estimations 11 of the $13(85 \%)$ second samples were consistent with the first ones in having more or less than five cells. A slightly smaller proportion, nine of the $13(69 \%)$ second samples,

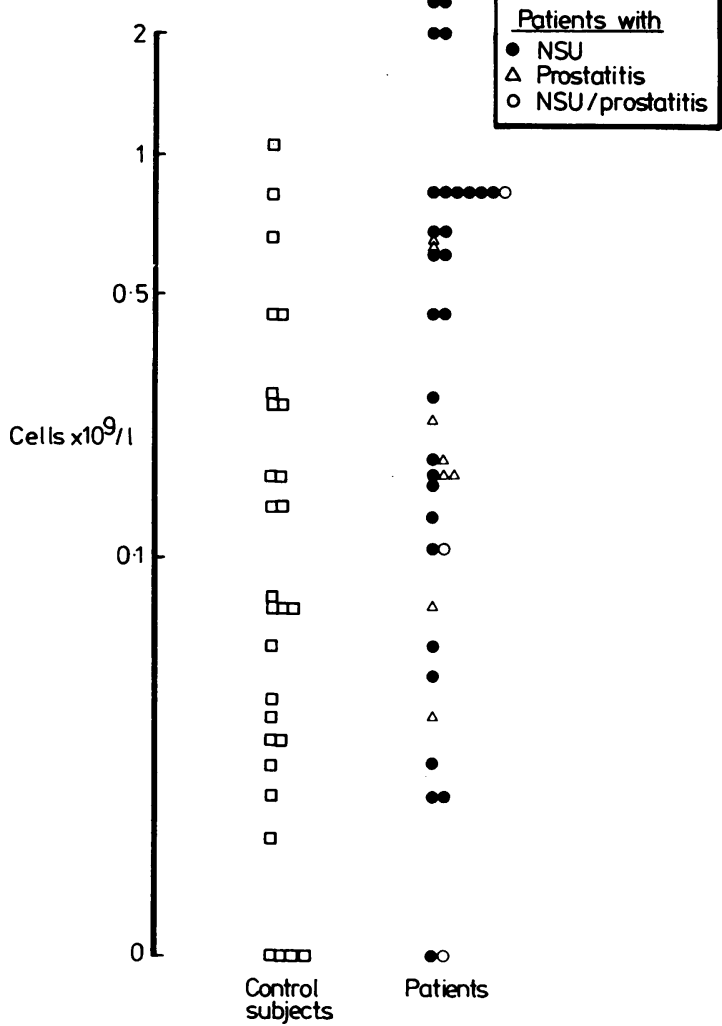

FIG 2 Leucocyte counts in expressed prostatic secretions of patients and controls. 
TABLE II Results of repeated investigations before treatment in 13 patients

\begin{tabular}{lcc}
\hline Investigations & First & Second \\
\hline Microscopy: & $7 \cdot 1$ & $7 \cdot 9$ \\
Mean cell estimate (cells/field) & 10 & 10 \\
Clumping (No of patients) & $0 \cdot 286$ & $0 \cdot 381$ \\
Mean cell count ( $\left.10^{9} / \mathrm{l}\right)$ & & \\
Culture: & 0 & 0 \\
$\quad$ Pathogens (No of patients) & 4 & 3 \\
\hline Saprophytes (No of patients) & \\
\hline
\end{tabular}

were consistent in showing clumping on microscopy. In EPS cell counts 11 of the $13(85 \%)$ second samples were consistent in having more or less than $0.5 \times 10^{9}$ cells $/ 1$ and isolation of micro-organisms was consistent in nine of the $13(69 \%)$. Results in five patients were consistent in all four repeat tests, in 11 patients in three repeat tests, and in all patients in two tests.

\section{FINDINGS BEFORE AND AFTER TREATMENT}

Figs 3 and 4 show the microscopical estimation of leucocytes and the EPS leucocyte counts before and after three months' treatment. The mean microscopical cell estimate before treatment was $5 \cdot 7$ cells

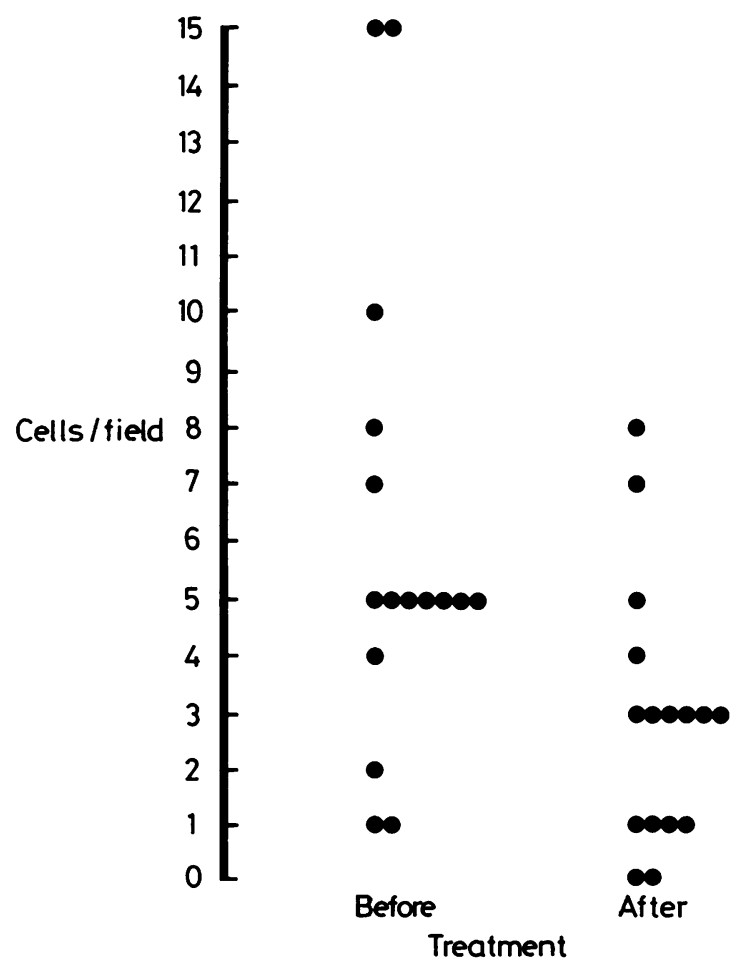

FIG 3 Microscopical estimation of leucocytes in expressed prostatic secretions before and after treatment.

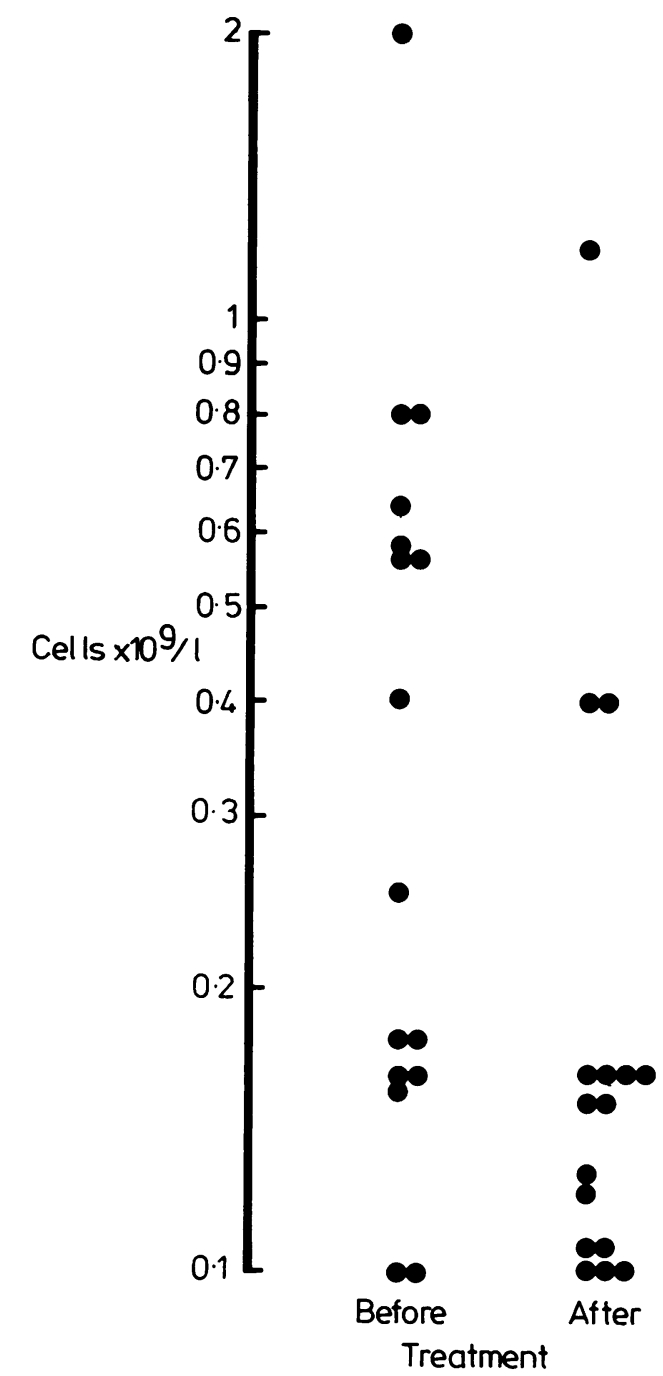

FIG 4 Leucocyte counts in expressed prostatic secretions before and after treatment.

per microscope field and after treatment $\mathbf{2} \cdot \mathbf{6}$ cells per microscope field. Clumping was present in 12 patients before and in four after treatment. The mean cell count was $0.466 \times 10^{9} / 1$ before treatment and 0.220 $\times 10^{9} / 1$ after treatment. After treatment there was a significant reduction in microscopical cell estimates $(T=27, p<0.05$, Wilcoxon's signed ranks test), cell counts $(T=9, p<0.01)$, and clumping (McNemar's test $p<0.05)$. No pathogen was isolated from any patient before or after treatment. Staph epidermidis with or without diphtheroids was isolated from 10 patients before treatment and from only five after treatment but this difference was not significant $\left(\chi_{1}^{2}\right.$ $=1.78 \mathrm{p}>0.1)$. 
If microscopical cell estimates are divided into those of more and less than five cells per microscope field before treatment the mean reduction for those less than five was from 3.9 to 2.9 cells per microscope field, whereas for those more than five it fell from 11 to $2 \cdot 8$ cells per microscope field. Similarly, if the cell counts are divided into those of more and less than $0.5 \times 10^{9}$ cells $/ 1$ before treatment, the mean for those less than $0.5 \times 10^{9}$ cells $/ 1$ fell from $0.169 \times$ $10^{9} / 1$ to $0.117 \times 10^{9} / 1$ whereas for those more than $0.5 \times 10^{9}$ cells $/ 1$ the mean cell reduction was from $0.848 \times 10^{9} / 1$ to $0.353 \times 10^{9} / 1$. We did not attempt to assess clinical features either before or after treatment as this would have been inaccurate. The general impression was of slow gradual improvement.

\section{Comment}

The findings were reproducible and show that the increased microscopical cell estimations and cell counts in the EPS of patients with symptoms of prostatitis and in patients with recurrent NSU, which were absent in the EPS of the controls, indicate the presence of prostatitis. Fewer patients showed these changes after three months of treatment with cotrimoxazole but in the absence of any group for comparison the improvement cannot be ascribed to the drug. No attempt was made to assess any change in symptoms after treatment.

Examination of the pretreatment findings suggests that the upper limit of normal for the EPS cell estimation was about five cells per $\times 40$ microscope field, and the upper limit for the cell count was about $0.5 \times 10^{9}$ cells $/ 1$ using the method described. These limits may be revised after further work and are lower than values previously given, ${ }^{910}$ but this is probably related to dilution of the EPS by urine still in the urethra. This dilution had to be accepted so that an adequate volume of EPS could be obtained.

Six $(21 \cdot 4 \%)$ controls had cell estimations and three $(10 \cdot 7 \%)$ cell counts above these limits. These pro- portions compare favourably with the $30 \%$ of abnormal microscopical findings in healthy men suggested by Oates. ${ }^{2}$ In addition, six $(21 \cdot 4 \%)$ controls had clumps of leucocytes. Sixteen $(\mathbf{4 1 \%})$ patients had cell estimates $>5$ cells per $\times \mathbf{4 0}$ microscope field and this agrees closely with the finding that $17(43 \cdot 6 \%)$ had cell counts $>0.5 \times 10^{9} / 1$. Twenty four $(61 \cdot 5 \%)$ patients had clumps of leucocytes, but a clump was defined as a minimum of two cells and perhaps this definition should be revised. With this proviso the method described appears to offer a means of diagnosing prostatitis in the absence of pathogens but it needs further evaluation. Once objective signs of prostatitis can be identified rational treatment of prostatitis can be assessed.

We thank Jane Wadsworth and Ruth Holt for valuable statistical assistance.

Presented at the spring meeting of the MSSVD in May 1979 at Lubeck.

\section{References}

1. Meares EM, Stamey TA. Bacteriological localisation patterns in bacterial prostatitis and urethritis. Invest Urol 1968;5:492518.

2. Oates JK. Prostatitis. Br J Hosp Med 1969; 2:556-61.

3. Blacklock NJ. Some observations on prostatitis. In: Williams DC, Briggs MH, Stanford M, eds. Advances in the study of the prostate. London: Heinemann, 1969, 38-55.

4. Thin RNT. Prostatitis after urethritis in Singapore. Br J Vener Dis 1974;50:370-2.

5. Alani MD, Darougar S, Burns DCMacD, et al. Isolation of Chlamydia trachomatis from the male urethra. Br J Vener Dis 1977; 53:88-92.

6. Simmons PD. Evaluation of the early morning smear investigation. Br J Vener Dis 1978; 54:128-9.

7. Leigh DA, Williams JD. Method for detection of significant bacteriuria in large groups of patients. J Clin Pathol 1964;17: 498-503.

8. Cowan ST, Steel KJ. Manual for the identification of medical bacteria. Cambridge: Cambridge University Press, 1975.

9. Anderson RU, Wellen C. Prostate secretion leucocyte studies in non-bacterial prostatitis (prostatosis). J Urol 1979; 121: 292-4.

10. Huggins C, McDonald DF. Proteolytic enzymes and acid phosphatase in the prostatic fluid in chronic prostatitis. $J$ Urol 1944;52:472-4. 